\title{
Revisitando as políticas educacionais do Paraná do período de 1983 a 1994
}

\author{
Jackelyne Corrêa Veneza ${ }^{1}$
}

\section{RESUMO}

O presente texto orienta-se no sentido de apresentar uma reflexão sistemática sobre o contexto proposto pelas políticas educacionais paranaenses, no período de 1983 a 1994. Estabelece também uma análise referente às relações entre essas políticas e os professores alfabetizadores no decorrer de cada gestão, destacando os principais pontos que influenciaram o ensino do segmento inicial do então primeiro grau.

Palavras-chave: política educacional, alfabetização, CBA, professor alfabetizador

As pesquisas, dentre outros assuntos, têm discutido as políticas educacionais, o estudo sobre a definição da função docente, o papel do professor na atualidade e a direção escolhida para as reformas dos cursos de formação de professores.

Podemos dizer, então, que o tema "formação de professores" tem sido estudado e experienciado não só com o intuito de avançar teoricamente, mas também como pano de fundo para as mudanças da linha teórico pedagógica das políticas educacionais. Está claro que as ações pedagógicas são vistas de forma diferenciadas a cada governo e que os resultados podem ser interpretados, diferentemente, em cada um dos períodos de gestão, fazendo com que, infelizmente, as pesquisas nem sempre sejam consideradas.

${ }^{1}$ Professora Mestre do Departamento de Métodos e Técnicas de Ensino da Universidade Estadual de Ponta Grossa.

Olhar de professor, Ponta Grossa, 2 (2):111-124, nov. 1999. 
Dentro das colocações já posicionadas, o texto propõe-se refletir sistematicamente a respeito do contexto proposto pelas políticas educacionais paranaenses $(1983$ - 1994) e das relações que entre elas e os professores alfabetizadores se estabelecem no decorrer de cada gestão. Trata dos principais pontos das políticas educacionais dos governos José Richa/João Elísio Ferraz de Campos (1983-1986), Álvaro Fernandes Dias/ Ary Velloso Queirós (1987-1990) e Roberto Requião/Mário Pereira (1991-1994), que influenciaram o ensino do primeiro segmento do Ensino Fundamental.

O Estado do Paraná sofre alterações significativas a partir de 1983, quando assumem o poder os governos estaduais do partido PMDB, escolhidos através de eleições diretas. No decorrer de doze anos, o Estado esteve governado por representantes desse partido.

No governo José Richa (19831986), as propostas pertencentes à política da educação foram elaboradas já para a campanha eleitoral. Bastante heterogêneas, defendiam a tarefa da escola numa educação denominada no programa de "libertária", na tentativa de harmonizar a política da educação à política de empregos da época, relacionada com a estruturação de uma nova sociedade, voltada ao crescente processo de industrialização e concentração de rendas. Buscavam também abrir espaço para que a comunidade escolar passasse a partici- par nas decisões da escola, iniciando pela eleição de diretores, metas que faziam parte do programa de governo.

Nesse programa denominado "Democracia e justiça social", destacam-se mais alguns pontos que parecem relevantes: reforma administrativa; descentralização da Secretaria de Estado da Educação - SEED; retomada do ensino público e gratuito, em especial do $1^{\circ}$ grau; reparo da rede física da escola e melhoria qualitativa; busca de qualidade de ensino; garantia de acesso e permanência do aluno na escola; qualificação do professor, valorizando-o no sentido de ser ele um profissional necessário à sociedade mais que para o exercício do magistério; melhoria de salário; cursos de aperfeiçoamento; e outros.

Mereceram relevância, nas ações efetivadas durante o mandato, a criação dos Núcleos Regionais de Educação - NRES; a definição da política educacional, que resultou no texto "Políticas da SEED/PR: fundamentos e explicitação", divulgado em 1984 pela Secretaria de Estado da Educação; a redefinição dos critérios temáticos do Conselho Estadual de Educação; a eliminação das taxas escolares; a eleição de diretores; a nãoobrigatoriedade do uso de uniforme na escola; e a ampliação da rede física escolar.

Alguns dados estatísticos sobre evasão e repetência das escolas estaduais, usados para diagnóstico do Estado do Paraná, na implantação das diretrizes de governo, mostram um 
quadro desolador, quanto aos alunos que saem do $1^{\circ}$ grau e ingressam no ensino de $2^{\circ}$ grau. Esse quadro serviu de alerta para o governo, no sentido de que a qualidade de ensino está no fato de a educação precisar ser alcançada por todos, para poder alterar a estrutura da sociedade e transformar-se num dos mecanismos de mudança.

A fim de rediscutir o que se pretendia, enquanto ensino público e gratuito, e garantir o acesso e permanência do aluno na escola, principalmente dos oriundos da classe trabalhadora, desafiaram-se os professores a oferecer às camadas populares “(...) por todos os meios formais e não - formais possíveis - o saber que é oferecido às classes com maior poder aquisitivo"(CUNHA, 1995, p. 234). Com a finalidade de melhorar o ensino e atingir a maioria da população para reconstruir a sociedade, são usadas, como fundamentação teórica, as recomendações de Dermeval Saviani: selecionar conteúdos relevantes aos alunos das classes populares, sem barateá-los.

Para promover a democratização, propunha-se a participação das comunidades escolares, como uma das respostas ao desejo da população em participar das decisões, ao mesmo tempo em que incentivavam-se os professores a procurar aprender junto aos pais, aos alunos, às associações, aos sindicatos, para melhor compreender o que ensinar, e a quem ensinar.

Quanto ao $1^{\circ}$ grau, o que se pode destacar, além dos pontos vistos anteriormente, é que no governo José Richa houve a opção por uma política de expansão do ensino do $1^{\circ}$ segmento, priorizando a transferência de recursos para as prefeituras por intermédio da FUNDEPAR, ou seja, a gestão caracterizou-se pela ênfase no ensino de nível local.

É como CUNHA revela:

em 1984, foi celebrado o Convênio de Cooperação Financeira entre o governo do estado e 306 municipios, que previa a transferência de recursos para pagar treze mil professores e pessoal de apoio contratados pelas prefeituras, mas que trabalhavam em escolas da rede estadual, isto é, nos prédios construídos pelo governo estadual, sem que se submetessem a concurso público (1995, p. 237).

O que parecia ser um grande espaço de atuação docente, acabou criando um processo de desvalorização dos mesmos profissionais, que recebiam salários bem mais baixos que os concursados da rede estadual e não tinham as mesmas vantagens dos funcionários públicos, já que eram regidos pelo regime de Consolidação das Leis do Trabalho - CLT. Nem sempre eram recebidos pelos estabelecimentos, pois geralmente, não permaneciam mais que um ano em cada escola, devido à forma de contrato.

Assim, não havia integração dos professores no estabelecimento de 
ensino porque eles chegavam quase sempre depois do início do período letivo, e não participavam das reuniões administrativas e pedagógicas iniciais. Muitos profissionais, pela instabilidade da situação, não assumiam as devidas responsabilidades dentro da escola e outros, ao contrário, por serem apenas contratados, desempenhavam-se com esmero e sentiam-se frustrados por não ter o trabalho reconhecido.

Muitas lutas foram e ainda são travadas por esses professores, que reivindicam desde o reconhecimento profissional até as perdas salariais.

$\mathrm{Na}$ tentativa de aproximar os conteúdos do currículo da escola à realidade social e política dos alunos, a Secretaria Estadual da Educação desenvolveu materiais pedagógicos e textos para os professores, no sentido de melhorar a qualidade de ensino.

Os materiais produzidos pela SEED foram trabalhados na escola por meio das Semanas Pedagógicas, que aconteciam no início de cada ano letivo. Para tanto, a SEED mandava textos que buscavam suscitar a análise da teoria com a prática real: direção, disciplina, avaliação, regimento escolar, planejamento curricular, participação dos pais na escola e outros assuntos mais tarde levantados pela comunidade escolar. Tudo isso para que não se fizesse planejamento no nível escolar, sem o conhecimento das políticas educacionais da gestão.

No espaço aberto para discussão, também se levantariam alternativas que deveriam resultar no plano educativo da escola, que deveria estar direcionado para os conteúdos e as metodologias de ensino.

As Semanas Pedagógicas resultaram em publicações no Jornal da Educação, criado pela gestão, o qual trazia vários artigos referentes às políticas da SEED. Tais artigos abordavam desde questões levantadas na escola até os fundamentos necessários para a construção de uma política libertadora (tese defendida no programa de governo).

Depois de muitas lutas, que implicaram em dois momentos de greve, houve na gestão os ganhos do piso salarial e da eleição para diretores. Quanto à melhoria da qualidade de ensino no $1^{\circ}$ grau, só existe a expressão numérica que indicava “(...) a redução dos índices de evasão e repetência na $1^{\mathrm{a}}$ série do $1^{\mathrm{o}}$ grau na rede estadual de ensino, de 38,8\% para 28,3\%, em 1983/1984". Segundo CUNHA (1995, p. 255), nada mais foi divulgado sobre o assunto.

Tentando reduzir os índices de evasão e repetência, e possibilitar a compreensão entre os saberes e valores da classe popular e da classe dominante, tal gestão depositou no professor de $1^{\circ}$ grau toda a "consciência" de ser o único responsável pela melhoria do ensino (melhoria implica sucesso; as duas expressões são, pois, redundantes!)

A segunda gestão, inicia-se com a posse de Álvaro Dias, em 1987, ainda pela legenda do PMDB. No que 
diz respeito à educação e ao ensino, $\mathrm{o}$ novo governo prioriza o projeto pedagógico sobre os demais - entre os quais os projetos de expansão e modernização da rede escolar, e de administração dos recursos do sistema educacional - e, por acreditar que a proposta de uma escola democrática possa a ser construída a partir da crítica da escola pública atual, procura o êxito da gestão na melhoria da qualidade educacional, oferecida no Estado do Paraná.

Para tal se propôs a reordenação do sistema educacional, visando à produtividade. Afinal, o Paraná apresentava índices alarmantes de reprovação dos alunos na passagem da $1^{\text {a }}$ para a $2^{\mathrm{a}}$ série do $1^{\mathrm{o}}$ grau, o que já fora diagnosticado na gestão anterior. Segundo dados do documento "Reflexões sobre Alfabetização: subsídios, da Secretaria de Estado da Educação" (1987, p. 2), do Estado do Paraná, o índice de reprovação era ainda bastante significativo. Depois de um ano de escolaridade, de cada cem crianças que ingressavam na escola pública do Paraná, em torno de $46,4 \%$ eram desestimuladas a continuar o processo de alfabetização (por evasão ou reprovação) que resulta da aplicabilidade de critérios pouco realistas.

É em tal contexto que o governo propõe a reorganização da escola pública do $1^{\circ}$ grau, criando o Ciclo Básico de Alfabetização (CBA), o qual tem como principal objetivo a reversão do fracasso escolar.
Na tentativa de eliminar a reprovação da $1^{\mathrm{a}}$ série, por meio de aprovação automática, o CBA abre caminho para várias ações de cunho pedagógico, entre os quais: reorganização dos conteúdos curriculares; definição dos conteúdos básicos para o $1^{\circ}$ grau; correção da distorção idade/série e reorganização da escola; criação de um programa de atendimento ao pré-escolar (0-6 anos); melhoria das condições de trabalho docente; reorientação do ensino da língua; definição de critérios para o trabalho pedagógico com as crianças das classes populares; e, principalmente, reconsideração das concepções de criança e de alfabetização.

As eleições diretas, criadas na gestão anterior, são mantidas porém com novas instruções para a candidatura: seria necessário um professor ou especialista, vedava-se a possibilidade de candidatura em mais de uma escola e não poderiam ser candidatos os diretores que já tivessem exercido dois mandatos sucessivos.

As ações traçadas para a reorganização da escola pública atingem diretamente as séries iniciais. Aliadas aos avanços das ciências humanas e sociais - desenvolvimento da lingüística, da psicologia, da sociolingüística e de outras áreas do conhecimento objetivam permitir melhor compreensão do sistema da escrita e, conseqüentemente, um redirecionamento do processo de alfabetização e do ensino da língua.

Espaços de estudo e discussão fo- 
ram abertos, sobre:

- concepção de homem, enquanto produto das relações sociais, sujeito da própria história e com liberdade para percorrer o próprio trajeto para errar e acertar;

- concepção de currículo, permeado pelas concepções de cultura e de homem, considerando o desenvolvimento da ciência e a influência da tecnologia;

- concepção de escola mais democrática, atualizada e competente, que propicie a todos a mediação entre o saber e o fazer;

- concepção de aluno, uma vez que não se pretende ensinar qualquer aluno, nem o abstrato, mas o concreto, proveniente das camadas populares;

- concepção de educador, que tem compromisso assumido com a formação do aluno, com a competência profissional, precisando considerar o aluno como sujeito e não como mero objeto do processo ensino-aprendizagem.

Apesar de todas as contribuições de estudo e análise, o que realmente se efetivou na aludida gestão, quanto ao $1^{\circ}$ grau, foi a implantação do CBA, em 1988, e a consolidação do Currículo Básico, em 1990.

Mesmo com um discurso democrático, a gestão caracterizou-se por momentos difíceis de lutas, atos arbitrários e violentos por parte do governo, os quais se consolidaram em duas grandes greves, ocorridas em 1988 e 1990. Foram momentos de desequilí- brio no desempenho dos profissionais, no sentido de que os professores tornaram-se apáticos e muito revoltados, dificultando a implantação eficiente das propostas governamentais.

Os docentes passaram a recusarse em participar dos cursos de capacitação docente que, por sua vez, também não conseguiam atender às suas necessidades reais e encaminhálos nas superações e nas incompreensões da nova concepção de alfabetização. Foi um dos momentos em que a escola mais recebeu materiais de qualidade e obras atualizadas de formação pedagógica e de literatura infantil. Porém, a falta de diálogo verdadeiro entre governo e professores fez com que o material não fosse utilizado de acordo com os objetivos da proposta. O Currículo Básico, elaborado por docentes atuantes em sala de aula da rede estadual e especialistas, foi recebido com desconfiança. Sabemos que sempre há resistência quanto ao desconhecido. Afinal, a fragmentação na formação do professor o torna inseguro em opinar e discutir. Assim, a falta de estudo, de fundamentação teórica e o não acompanhamento e avaliação do Currículo Básico pela SEED, não lhe permitiram a eficácia.

Do contexto de insatisfação e inseguranças quanto às propostas governamentais, passa-se para o governo Roberto Requião, iniciado em 1991. Pode-se dizer que, no aspecto educacional, pretendia esse governo 
ser uma nova era para a escola pública paranaense, apregoando propostas de modernidade, qualidade de ensino, gestão democrática, eficiência e participação comunitária. Na tentativa de mostrar o novo, o governo Requião oculta que as propostas aproximam-se da gestão anterior, passando a idéia de que começa uma etapa totalmente nova.

O programa educacional intitulado "Uma Educação para a Modernidade", proposta de ações governamentais para o ensino do Paraná (PMDB - 1990), elege a educação como meta prioritária de governo. Entretanto, nenhuma estimativa da situação educacional paranaense fora realizada, e nem mesmo uma simples análise da política educacional, proposta pelo PMDB, desde as gestões anteriores. E as novas ações são efetivadas, medidas são implantadas, sem preocupações em dar continuidade ao que estava dando certo e rever o que estava apresentando falhas.

Para garantir a reorganização e a qualidade da escola pública, foram encaminhados na gestão os seguintes pontos: municipalização do ensino fundamental de $1^{\mathrm{a}}$ à $4^{\mathrm{a}}$ série (iniciada na gestão anterior com o Protocolo de Intenções entre Estado/Município, que procurava partilhar serviços e encargos para a universalização do ensino); consolidação do Ciclo Básico de Alfabetização (não efetivado de acordo com o discurso); elaboração do Projeto Político Pedagógico pelas escolas; proposta do Regimento Es- colar Único (rejeitado pela classe do magistério, colocado em discussão e ainda hoje questionado); implementação do Currículo Básico para a escola pública paranaense; autonomia e gestão democrática das escolas; "capacitação" dos professores da Rede Estadual, articulação e integração dos três graus de ensino no Programa de Integração/Capacitação; eleição de diretores substituída pela consulta à comunidade; eliminação da reprovação de $1^{\mathrm{a}}$ a $4^{\mathrm{a}}$ série, ou seja, extensão do Ciclo Básico para quatro anos (Decreto n. ${ }^{\circ} 2.325$, de 25 de maio de 1993).

Apesar do discurso descentralizador, as ações dessa gestão acabaram sendo centralizadas no âmbito da SEED, sem discussão com os professores e sem a participação efetiva da comunidade para a implantação.

Pela forma como foram implantadas as propostas é que percebemos determinadas oscilações no governo Requião, que ora passa por medidas democratizantes, ora se revela centralizador e autoritário. Corrobora-se o exposto, por exemplo, na substituição da eleição de diretores por uma consulta à comunidade escolar, sem que ela fosse realmente consultada e preparada para tal; na apresentação do Regimento Escolar Único; nas formas de ação adotadas para a municipalização do ensino; na instituição do Ciclo Básico de quatro anos, por decreto.

Proposições que poderiam ser consideradas de caráter democrático, 
seriam as propostas de autonomia e gestão participativa das escolas, e de criação dos Conselhos Escolares. Porém, o que seria necessário para dar continuidade às ações já efetivadas na gestão anterior e que muito contribuíram para diminuir as taxas de evasão e repetência, como o Ciclo Básico de Alfabetização e o Currículo Básico, não receberam o apoio e a implementação necessários.

Na tentativa de reverter as precárias condições de ensino na rede pública do Paraná, as três gestões abordadas deixaram certos avanços e alguns recuos. O governo Richa abre o caminho para a reflexão sobre os dados alarmantes de evasão e repetência da $1^{\mathrm{a}}$ série do $1^{\circ}$ grau. Procura rediscutir e definir o verdadeiro papel do ensino público e gratuito, bem como a compreensão de quem é a clientela, mas tal reflexão permanece apenas dentro da SEED e para alguns, sem efetivar a participação da comunidade escolar. Desafia os professores a dar conta de um fracasso histórico e não proporciona cursos de aperfeiçoamento adequados às suas necessidades. Amplia a demanda docente da rede estadual, ao implantar a contratação de professores pelo regime de consolidação das Leis do Trabalho - CLT. A despeito das contratações, acaba criando uma classe diferenciada, dentro do imaginário, que mais tarde acabou sendo discriminada pelos próprios companheiros de trabalho, como já foi dito anteriormente.

As semanas pedagógicas, que poderiam ser espaços de discussões so- bre os problemas do cotidiano escolar, não facilitaram a construção de um conhecimento real da escola, tendo em vista que os textos e as questões a serem nelas discutidas eram estabelecidos pela SEED, enquanto as necessidades dos professores continuaram não sendo atendidas.

Como muitos dados a respeito da escola de $1^{\mathrm{a}}$ à $4^{\mathrm{a}}$ séries não foram publicados, as contribuições da gestão, que ficaram mais no nível teórico, apenas indicaram aspectos para a discussão sobre o papel do professor e do aluno. A falta de registros do desenvolvimento das propostas para as séries $1^{\mathrm{a}}$ a $4^{\mathrm{a}}$ não permitem uma análise real dos avanços.

Já na gestão Álvaro Dias podemos dizer que as medidas tomadas imprimiram mudanças significativas no sistema de ensino de $1^{\circ}$ grau na escola, nas ações do professor alfabetizador e, conseqüentemente, no aluno e no sistema de ensino. Num primeiro momento, a implantação do Ciclo Básico da Alfabetização provoca uma profunda reflexão sobre o conceito de educação, de alfabetização, de avaliação e de aluno.

Com um olhar histórico sobre a década de 80 no Estado do Paraná, observa-se que se operou uma ruptura em nível político, que do discurso sobre a Reconstrução Nacional, do Sistema Educativo, das Liberdades Políticas e de Cidadania, abriram-se condições para um novo símbolo (conceito) de educação, a chamada "Concepção Histórico-Crítica", que 
fundamentou a implantação do Currículo Básico, em um denominado segundo momento.

Aos professores do primeiro segmento do ensino de $1^{\circ}$ grau, da rede estadual - considerados como classe trabalhadora - foi apresentada, na implantação da proposta CBA, uma concepção de educação fundada nas relações de produção capitalista, tentando-se absorver a pedagogia Histórico-Crítica na prática pedagógica. Esse fato que contribuiu para certos avanços na discussão educacional, promovendo confrontos entre os professores dos três graus de ensino.

A contradição, que se estabeleceu entre os pressupostos teóricos da pedagogia Histórico-Crítica e o sistema econômico-político-social, contribui para uma não-reflexão sobre a política educacional direcionada para o Ensino de $1^{\circ}$ e $2^{\circ}$ graus. Tais contradições geraram as seguintes constatações e o decorrente questionamento: a concepção de alfabetização, baseada na Pedagogia HistóricoCrítica, não é a mesma que se apresentava nas escolas e como não houve um acompanhamento significativo ainda não o é; o CBA, que iniciou como "continuum" de dois anos, não foi compreendido pela comunidade escolar em seus elementos básicos (o que podemos constatar pelo quadro de reprovação das $3^{\text {a }}$ séries da época). Mais tarde, como medida preventiva, transformou-se em continuum de quatro anos (a dificuldade passou para as $5^{\mathrm{a}}$ séries). Hoje se pensa num “continuum” de oito anos: será que não vamos passar tais falhas para todo o $2^{\circ}$ grau?

Um processo de incertezas instala-se prioritariamente na figura do professor e na competência que, pela "nova" forma de compreender a alfabetização, passou a denominar-se de professor alfabetizador, e na competência desse professor.

A partir do CBA, considera-se o professor alfabetizador como o mediador entre o aluno e o conhecimento historicamente produzido. Assim, ele precisa compreender a alfabetização na perspectiva do significado de aprender a escrever, ou seja, tomar como objeto a própria língua, ampliando o entendimento de ler e escrever, reconhecendo-lhe os valores e usos sociais.

Para fundamentar a proposta curricular, a SEED usou o conceito educacional de Dermeval Saviani, conceito este denominado, desde 1984, de Pedagogia Histórico-Crítica; a implantação do CBA; as reflexões sobre a reestruturação dos conteúdos das áreas do conhecimento, resultantes dos encontros e cursos promovidos pelo Departamento de Ensino de $1^{\circ}$ grau e pelos Núcleos Regionais.

O Currículo Básico, fundamentalmente, procura rediscutir o caminho que a escola tem percorrido; a importância da escola básica e a necessidade da consciência crítica e da postura política do professor para lutar em defesa da escola pública, gratuita e de qualidade. 
Por tudo isso e para tudo, precisou-se repensar o conceito sobre educação, com base sobretudo em SAVIANI, para quem

A educação existe, pois, para propiciar a aquisição dos instrumentos que possibilitam o acesso ao saber elaborado (ciência), bem como o próprio acesso aos rundimentos desse saber. As atividades da escola básica devem se organizar a partir dessa questão ... (1991, p.23).

Pelo que se questionou, necessário se faz que os professores se sintam agentes da história, compreendendo as mudanças das formas de produção, para que possam eles analisar as novas formas de educação, avaliando-lhe as teorias e se posicionando com fundamento.

Educar é também produzir e, consequentemente, provocar mudanças. Para tanto, é imprenscendível que o professor saiba selecionar os conteúdos, de modo que os alunos

... não apenas assimilem o saber objetivo enquanto resultado, mas apreendam o processo de sua produção bem como as tendências de sua transformação (SAVIANI, 1991, p. 17).

Tendo em vista o contexto supracitado, a escola precisa organizar-se para possibilitar o acesso ao conhecimento elaborado e não-frag- mentado, e também rever vários pontos, tais como: o entendimento sobre currículo; os meios utilizados para propiciar o saber; o tempo destinado em calendário, a fim de aprender e ensinar; o papel da escola no processo de democratização da sociedade; a competência técnica e o compromisso político dos profissionais da educação.

Aqui estão apenas alguns aspectos suscetíveis de discussão estudados e analisados pela comunidade escolar, quando da implantação do Currículo Básico. Mas, como fazer os encaminhamentos, se não se teve tal fundamentação? E se a equipe pedagógica das escolas não foram preparadas para orientar as discussões e se, ainda, os cursos de aperfeiçoamento promovidos pela SEED apenas propagandeavam a Pedagogia Histórico-Crítica e não propiciavam ao profissionais da educação uma real compreensão da mesma?

Urge utilizar o gesto, o jogo, o brinquedo, o desenho, o significado do nome, enquanto palavra-texto; o texto como núcleo de trabalho com a língua escrita; a produção dos textos dos próprios alunos, para trabalhar em sala de aula e já não precisar dos livros didáticos; conhecer diversos tipos de textos, reestruturá-los e avaliálos não mais em momentos únicos; senão considerar o processo de apropriação do aluno, em relação ao conteúdo trabalhado, realizando diagnósticos contínuos, tornando a forma de avaliar cumulativa e processual.

Como referência de leitura, eram 
indicados Vygotsky, Leontiev, Luria, Geraldi, Abaurre, Freire, Freinet, Franchi, Smolka, Lemle, Kramer, entre outros. Porém, parece se ter esquecido é que tais fontes não eram encontradas com facilidade na época; os professores dos cursos de formação inicial, inclusive, também não as conheciam e, portanto, os cursos de capacitação não tinham muito a oferecer.

VILLAS BOAS reforça essa posição, quando assevera:

... sabemos que toda e qualquer metodologia implica referências teóricas determinantes e um compromisso com o processo histórico-social, e nestas condições, pressupõe uma postura em relação à educação vista em seu contexto mais amplo, e nos múltiplos aspectos em jogo na sala de aula por mais particulares que sejam (1988, p. 12).

Assim, importante é entender que o processo de Alfabetização se apresenta complexo, múltiplo, cheio de condicionantes sociais, culturais e políticos, influenciando os métodos utilizados para leitura e escrita, a seleção de material didático (principalmente pela adoção ou não de cartilha). Contudo, necessário se faz que os entendimentos relativos a tais condicionantes e influências estejam presentes na formação do alfabetizador.

Apesar do avanço considerável na compreensão teórica do processo de alfabetização, não se tem evitado que o fracasso, no início da escolarização, ultrapasse as fronteiras tão somente como um problema educacional, quando o aspecto seria mais abrangente: esse fracasso é, na verdade, um problema sócio-políticoeconômico.

Justamente porque não basta mudar o referencial teórico, é preciso dar tempo para se conhecer a proposta, oferecer condições não só materiais, para a sua execução, como também promover a formação contínua dos professores nela envolvidos, o acompanhamento e a avaliação do que se está propondo.

Vale lembrar que a problemática é evidente, quando no governo Requião o CBA é simplesmente esquecido pela SEED. Apenas o discurso da necessidade de se haver condições propícias para o CBA e a implantação autoritária do CBA foram, em quatro anos, as atitudes tomadas. Se os professores fossem questionados, saber-se-ia que não haveria condições para a implantação dos quatro anos, principalmente porque não fora realizada uma avaliação real do CBA - "continuum" de dois anos. Portanto, o que houve foi apenas uma soma de dificuldades.

Foi também um fechar de olhos do sistema para a falta de professores que, nas unidades escolares, efetivassem o "continuum" de dois anos. Por conseguinte, a maioria dos profissionais que trabalharam no CBA eram do regime CLT e, ao final de cada ano, 
tinham que mudar de escolas ou passar pela pressão de iniciarem o ano vindouro desempregados. Havia, então, uma grande ruptura no entendimento de que o CBA implica a necessidade de o professor alfabetizador acompanhar a turma da primeira para a segunda etapa.

Por motivos financeiros, pela falta de espaço físico e de docentes para trabalhar, o contraturno foi fechado pelo sistema. Contudo, não se pode esquecer que o trabalho a ser desenvolvido, em outro turno, com alunos que necessitem de maior tempo para a apropriação dos conteúdos, faz parte das condições necessárias para a efetivação do CBA.

Observa-se, também, que o Currículo Básico, sem a devida avaliação da SEED, deixou de ser discutido pelas escolas.

Assim, os índices de evasão e repetência, após as três gestões, continuaram altos, mudando somente a série em que ocorriam. Isso denota que os profissionais da educação continuaram sem condições de transformar de modo adequado a situação vigente.

Não se pode ignorar os avanços teórico-práticos, proporcionados pelas três gestões, nem o fato de que a negação de algumas medidas que haviam sido propostas em uma e outra gestão, só serviu para a descontinuidade do que já estava caminhando para a superação das dificuldades.

É preciso ter presente que a sociedade atual exige que se prepare mão-de-obra altamente especializa- da e, consequentemente, de melhor escolaridade. Porém, se não se investir de modo consistente e qualitativo na formação dos professores, com certeza, contribui-se para o aumento do índice de pessoas desqualificadas e com mínimas condições de sobrevivência.

Dentro de tal quadro, a década de 90 tem se caracterizado por uma tentativa de superação da história já vivida. Podemos denominá-la, no momento, de crise dos paradigmas. Trata-se, portanto, de uma busca de caminhos e respostas que contribuam para compreender a educação necessária à sociedade pós-industrial.

É, por assim dizer, fundamental reavaliar o CBA, o Currículo Básico e o papel dos professores alfabetizadores sob o ponto de vista políticopedagógico, a fim de que se possa superar a dificuldade em compreender a distância entre o conceito de alfabetização e o fazer pedagógico existente.

Atualmente, existe uma busca para ultrapassar a crise vivida pela educação. Mas, a categoria profissional dos docentes continua com dificuldades salariais, com fragmentações na formação e sem recursos para investir no desenvolvimento pessoal e profissional.

Tendo em vista os dados atuais do índice de analfabetismo no país, compreende-se que o problema da formação do educador continua constituindo um tema de relevante importância a ser investigado, especialmente no 
que se refere à alfabetização, que pode ser considerada a porta de todo o conhecimento.

\section{REFERÊNCIAS BIBLIOGRÁFICAS}

1 BONAMINO, Alécia Maria Catalano de. Contribuições para estudos de política educacional. [Texto mimeografado apresentado na $16^{\mathrm{a}}$ Reunião ANPED, realizado em setembro/1993].

2 CUNHA, Luiz Antonio. Educação, estado e democracia no Brasil. São Paulo: Cortez, 1995.

3 GARCIA, Regina Leite. A formação da professora alfabetizadora: reflexões sobre a prática. São Paulo: Cortez, 1996.

4 HELlER, Agnes. O cotidiano e a história. São Paulo: Paz e Terra, 1985.

5 LOWY, Michael. Método dialético e teoria política. São Paulo: Paz e Terra, 1985.

6 MAINARDES, Jefferson. Ciclo básico de alfabetização: da intenção à realidade (avaliação do CBA no município de Ponta Grossa - PR). UNICAMP/ Campinas, 1995. (Dissertação de Mestrado).

7 NOGUEIRA, Francis Mary Guimarães. Políticas educacionais do Paraná: uma versão institucional da proposta pedagógica dos anos oitenta. PUC/
SP, 1993 (Dissertação de Mestrado).

8 OLIVEIRA, Romualdo Portela de.(org). Política educacional: impasses e alternativas. São Paulo: Cortez, 1995.

9 PARANÁ, Secretaria de Estado da Educação. Departamento de Ensino de $1^{\circ}$ grau. Reflexões sobre alfabetização: subsídios. Curitiba: SEED/DEPG, 1987.

10 — Secretaria de Estado da Educação. Departamento de Ensino de $1^{\circ}$ grau. Reorganização da escola pública: proposta preliminar de trabalho. Curitiba: SEED/DEPG, 1987.

11 - Secretaria de Estado da Educação. Departamento de Ensino de $1^{\circ}$ grau. Reorganização da escola pública - início com a implantação do Ciclo Básico Curitiba: SEED/DEPG, 1988.

12 _ Secretaria de Estado da Educação. Currículo básico para a escola pública do estado do Paraná. Curitiba: SEED, 1990.

13 SAVIANI, Dermeval. Pedagogia histórico-crítica: primeiras aproximações. São Paulo: Cortez, 1991.

14 VILLAS BOAS, Heloísa. Alfabetização: outras questões, outras histórias. São Paulo: Brasiliense, 1988. 


\section{DISPOSITIVOS LEGAIS}

1 DECRETO Estadual $\mathrm{n}^{\circ} 2545$, de 14 de março de 1988. Diário oficial do Estado, $\mathrm{n}^{\circ} 2.731$, de 15 de março de 1988, p.1. (Institui o Ciclo Básico de Alfabetização nas escolas de $1^{\circ}$ grau da Rede Estadual de Ensino).

2 DECRETO Estadual no 2325 , de 25 de maio de 1993. Diário Oficial do Estado, nº 4.019 , de 25 de maio de 1993, p.3. (Institui o Ciclo Básico de Alfabetização de 4 anos nas escolas de $1^{\circ}$ grau da Rede Estadual de Ensino).

3 RESOLUÇÃO - SEED n ${ }^{\circ} 744 / 88$, de 22 de março de 1988. Diário Oficial do Estado, ${ }^{\circ}$ 2.740 , de 28 de março de 1988, p.11. (Autoriza a implantação do Ciclo Básico de Alfabetização).

4 RESOLUÇÃO - SEED n ${ }^{\circ} 6.342$ / 93, de 29 de novembro de 1993. Diário Oficial do Estado, $\mathrm{n}^{\circ} 4.155$, de 09 de dezembro de 1993, p.22. (Implantação do Ciclo Básico de Alfabetização de quatro anos).

5 RESOLUÇÃO - SEED n ${ }^{\circ} 1.599$ / 94, de 22 de março de 1994. Diário Oficial do Estado, $\mathrm{n}^{\circ}$ 4.242, de 14 de março de 1993 , (Retifica a Res. 6.342/93). 